\title{
Usable Socio-Economic Science for Rangelands
}

\author{
By Mark W. Brunson, Lynn Huntsinger, Urs P. Kreuter, and John P. Ritten
}

\section{On the Ground}

- Because humans depend on rangelands for a wide variety of ecosystem goods and services, they have a large stake in research that explores supply and demand for those goods and services.

- Scientists and science users who ranked 142 separate rangeland issues chose a socio-economic concern as most pressing: How to help rural communities plan for, adapt to, and recover from impacts of increased social, economic, and ecological variability.

- Cross-jurisdictional stewardship is required to address many rangeland problems, so it is important to find ways to encourage and assist collaborative management efforts.

- Decision makers and citizens need better ways to sift through the conflicting claims and conclusions available from a growing number of information sources.

- Rangeland communities, and the land itself, require a steady supply of individuals who are both willing and able to choose careers in rangeland occupations.

Keywords: ecosystem services, ranching, rural communities, Sustainable Rangelands Roundtable.

Rangelands 38(2):85-89

doi: 10.1016/j.rala.2015.08.004

(C) 2016 The Society for Range Management

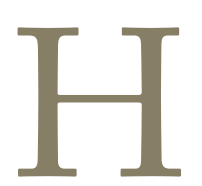

umans depend on rangelands in more ways than many people realize. Just about anyone can tell you that rangelands provide forage for livestock and beef production, settings for hiking or off-highway vehicle experiences, and habitat for wildlife. Fewer may realize that rangelands supply the water used by most people in highly populated US western states such as Texas $^{1}$ and California, ${ }^{2}$ or that most of the solar, wind, biofuels, and hydrocarbon-based energy in the United States is derived from facilities on rangelands. ${ }^{3,4}$ In the states with the fastest-growing populations, rangelands are experiencing significant conversion to intensive agriculture and residential subdivisions. ${ }^{5}$ It follows, then, that researchers increasingly must work to understand the numerous benefits that rangelands provide to meet human needs.

It also makes sense that because humans are dependent on rangelands for many ecosystem goods and services, ${ }^{6,7}$ they have a major stake in the outcomes of research that explores the supply and demand for those goods and services. The term "usable science" describes science that meets the changing needs of decision makers at multiple scales, from the individual ranch to the nation as a whole. ${ }^{8}$ It is difficult to imagine fields of study where it would be more critical to consult with decision makers when choosing research priorities than the social and economic sciences. This is reflected in results of an issue prioritization exercise conducted as part of a workshop on Future Directions for Usable Science for Rangeland Sustainability, held from 2 to 5 June 2014, in Ardmore, OK (see Maczko et al. of this issue). When participants ranked 142 identified issues proposed by five working groups (water, animals, vegetation, soils, and socio-economics), the No. 1 ranked issue overall came out of the Socio-Economics Working Group: understanding and managing for variability (climate, drought, fire), adaptation, and recovery. Clearly this is a critical issue for rangeland decision makers but is also an extraordinarily broad topic that could generate an almost unlimited number of researchable questions. Our principal challenge as members of the Socio-Economics Working Group was to identify questions that could yield the information most desired by decision makers, and that could be defined clearly enough so that high-quality research would be feasible.

No single field of study encompasses the term socioeconomics. Our working group included both users (decision makers) and producers of research, with backgrounds in resource economics, applied social science, and rangeland ecology. As interdisciplinary applied scientists, we are experienced at thinking across disciplinary boundaries. Even so, we found that formulating focused research questions within this topical area was challenging. As noted previously, the issues the group identified initially were very broad. There was not enough time to identify research questions that could cover all the various facets of an identified issue. For that reason the questions we settled upon might be best described as research programs that could cover a number of individual research projects over a period of years. 
A second challenge, which may be especially applicable to socioeconomic research, is that the answers our stakeholders desired were not always ones that could flow from scientific study. For example, when discussion focused on getting the right sorts of information to knowledgeable users in an accessible form, among the first questions raised was, "How can we make sure the public hears the truth about agricultural production when there are so many groups out there spreading biased or false information?" For most scientists, this question is fraught with untested assumptions, including that the person who asks it knows the "truth" and that other groups are "biased." Instead, most scientists are focused on producing testable, scientific information that can be used to inform decisions. Some social scientists do study persuasion, but their work tends to focus on the psychological processes and factors that lead people to heed a message and act upon it, or on identifying factors that influence how different audiences might respond to the same information.

For that reason it took us a while to agree upon a researchable problem related to this suggestion, which was: What are the rangeland information needs of different audiences, and what are the barriers and opportunities for information transfer to those various audiences? Such a research agenda would not try to suggest what people should know - that is a normative judgment, the purview of policy rather than science. Instead, it would identify what sorts of information each audience seeks and compare it to information the members of that audience tend to possess. Then it would identify factors preventing the audience from getting the information it seeks (e.g., communicators don't provide it, or they do provide it but not in a form that's useful to that audience), as well as opportunities for lowering those barriers to information flow.

Despite those caveats, our group was able to identify 30 socioeconomic issues that the research producers and consumers agreed were worthy of pursuing research. Prioritization by the participants in the entire workshop identified four socioeconomic issues of greatest concern, which our working group then explored in depth. These were:
- Understanding and managing for variability (climate, drought, fire), adaptation, and recovery (No. 1 on the overall list of 142 issues);

- Understanding and creating incentives to improve stewardship across boundaries (No. 10);

- Getting the right kinds of information to knowledge users in a form they can use (No. 11);

- Attracting new generations to make a living in rangeland agriculture and associated environmental fields (No. 19).

\section{Research Questions to Address High-Priority Issues \\ How do rural communities best prepare for, adapt to, and/or recover from impacts of increased environmental and socio-economic variability?}

Rangelands today, and the communities that depend on them, are changing in ways that have no historic precedent. Climate change, expansion of renewable energy facilities, and rapid growth of urban and suburban areas (Fig. 1) are just some of the environmental and socioeconomic processes that can demand responses from rangeland decision makers from the ranch scale to the national scale. Often the best policy solutions come when decision makers can review results of past successes or failures. If there are no prior models for comparison, insights from new or existing scientific research can be the best substitute. For example, researchers have explored why some communities in the Southwest recovered after catastrophic wildfire more quickly than others. ${ }^{9}$ Scientists could provide insight for decision makers by exploring the implications of that research for understanding recovery for communities devastated by unprecedented drought. Other research might explore factors that enhance or restrict social resilience in rural communities undergoing rapid growth due to new industries, or compare strategies employed by communities to prepare for unprecedented change.

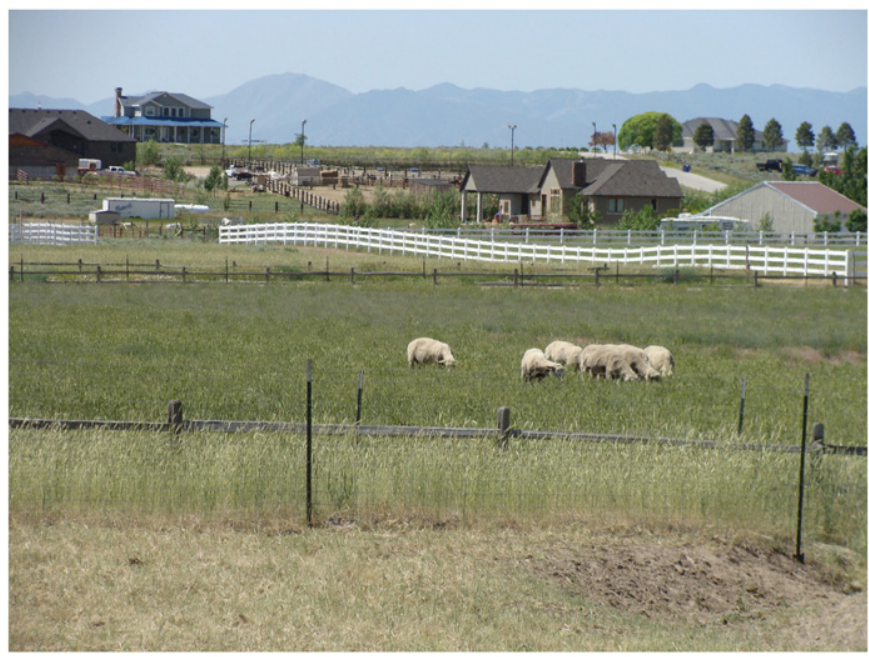

Figure 1. The rapid growth of exurban subdivisions such as this one near Cedar Fort, Utah, is just one of several unprecedented changes confronting rangeland decision makers. (Photo courtesy Mark Brunson). 
Addressing this issue is important not simply because our knowledge is limited, but also because the issue is relevant at any scale from local to international. Moreover, it affects an especially broad set of beneficiaries, as every economic or political sector must learn how to cope with such dramatic changes as we now anticipate across US rangelands. Studies of change must themselves adapt to changing conditions; therefore we expect that a research program focused on these issues would have to provide both immediate (shortterm) results and long-term insights based on time-series studies. Sources of funding for such research would likely come from a variety of government, foundation, and industry sources-necessary not only because the range of potential studies is so broad, but also because no single source of funds could support all of the research that might be needed.

\section{What motivates landowners to cooperate across boundaries for environmental stewardship, and how can that information be used to create or improve incentives (or reduce disincentives) for cross-boundary cooperation?}

Many troublesome issues confronting rangeland decision makers cannot be effectively addressed within a single property or jurisdiction. Goals such as controlling invasive species, restoring natural fire cycles, improving habitat for threatened wildlife, or protecting key watersheds must be achieved through stewardship that crosses boundaries. Often the productive capacity of an area can be increased if there is greater collaboration among entities whose lands are best suited to provide different ecosystem goods or services (Fig. 2). This idea was a driving force behind initiatives launched in the 1990s, such as ecosystem management in the United States or LandCare in Australia. However, participation in such efforts often has been sporadic. Some individuals have wished to participate but lack time or resources to do so. Others refuse to join, sometimes due to past negative experiences. ${ }^{10}$ Burnout has been a consistent problem for multi-jurisdictional partnerships. ${ }^{11}$ Conversely, prospective participants may ignore collaborative efforts until a crisis is perceived (e.g., if public land livestock permittees fear that an ongoing planning process could lead to loss of forage), joining only when tensions are highest and the likelihood of finding an amicable solution is reduced. If cross-boundary stewardship is to be a greater part of rangeland management strategies, research is needed that can point toward ways of improving participation rates in noncrisis times, as well as the efficiency of multijurisdictional partnerships. This includes knowing why some people participate and others do not, and also what options might exist for improving participation.

This research has high priority because the need for cross-boundary stewardship will only grow as rangeland ownership becomes increasingly fragmented while wildfires and non-native species invasions expand in size. The impacts of actions on one property can negatively affect conservation or production on adjacent properties. ${ }^{12}$ It would be valuable to compare results of studies conducted at relevant scales but in different regions - for example, a largely public land watershed in the interior West and a largely privately owned watershed in the Great Plains. Government farm programs and conservation foundations are the most likely sources for funding.

What are the rangeland information needs of different audiences, and what are the barriers and opportunities for information transfer to those various audiences?

As we noted previously, information is increasingly available with rapid growth in the number and accessibility of social media worldwide. A side effect of this information explosion is that the products of these information outlets are of varying quality and veracity. Some sources may provide scientifically valid information but present it selectively to build support for certain policy outcomes. Other sources may report hearsay or wishful thinking. This situation is unavoidable, because in a democracy it is crucial that the information sphere be unregulated. However, the work of rangeland decision makers is made easier when their

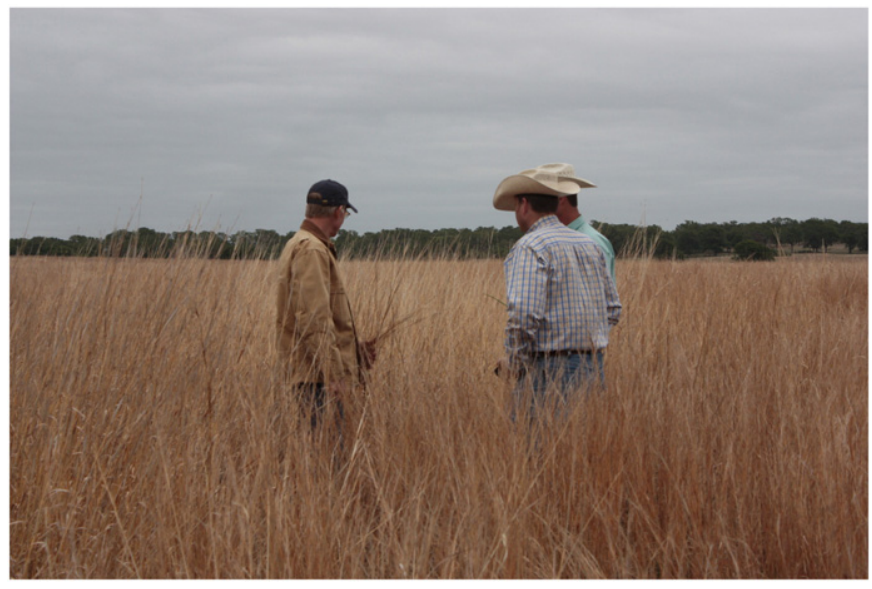

Figure 2. As rangeland ownership is increasingly fragmented, there is greater need for cross-boundary stewardship such as this rangeland planning effort near Bowie, Texas. (Photo courtesy John Tanaka). 


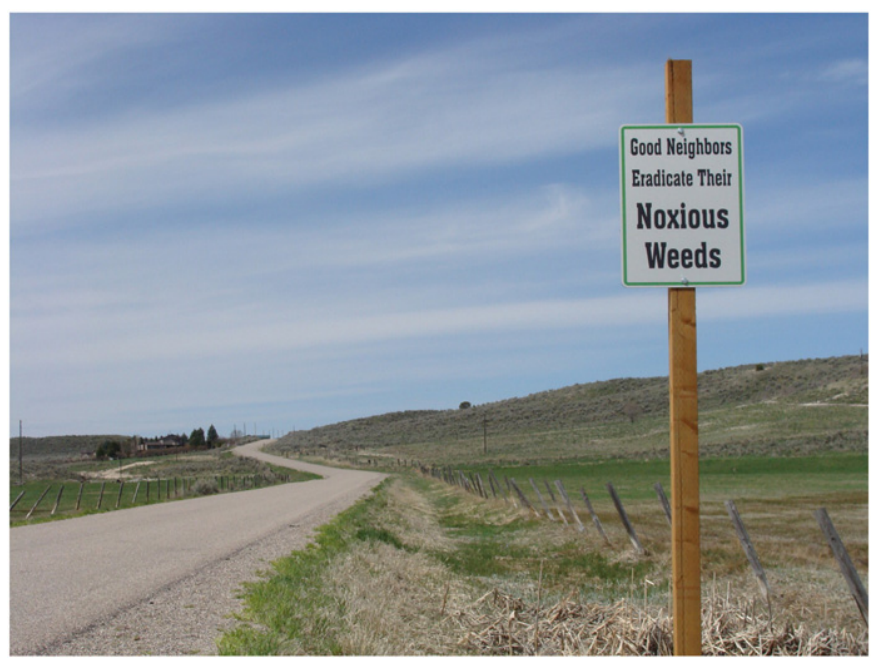

Figure 3. Creative information campaigns, such as this weed management outreach campaign near Arimo, Idaho, are needed to get information to audiences that are more and more disconnected from traditional rangeland uses and occupations. (Photo courtesy Mark Brunson).

stakeholders are well informed. Different audiences need different types of information, depending on the benefits they hope to gain from rangelands, as well as their familiarity with range management. It is important that those audiences are able to find the information they need when they need it (Fig. 3). While decision makers cannot dictate where their constituents or stakeholders get their information, they can try to make scientifically-based information more easily located and understood.

We ranked this question as having high priority because the demographic makeup of rangeland communities is changing rapidly in many areas. An ever-smaller proportion of the US population is directly connected to agriculture or natural resource management. Also, in areas of the West experiencing rapid population growth, a large number of in-migrants have had little experience with rangelands and their management. Getting information to these rapidly expanding audiences is especially important. Research on information accessibility and audience preferences can be conducted at any scale from local to national, and can be accomplished relatively quickly with funding that could come from a variety of sources.

\section{What are the barriers and opportunities for people to enter and persist in rangeland occupations, and how can we use information about barriers and opportunities to increase the number of adults who choose such careers?}

The sustainability of rangeland enterprises and communities depends on a continual supply of landowners and managers, as well as individuals who can work in support activities from sales to science to policy making. This is important not only to those whose livelihoods depend directly on flows of ecosystem services from rangelands, but to entire communities and regions. Research has shown that depop- ulation in the northern Great Plains-largely driven by changes in economic structure and water supply that led to the decline of local agriculturally based industries-increases communities' vulnerability to natural hazards such as drought or catastrophic storms and impairs their ability to recover from such events. ${ }^{13}$ Meanwhile, economic forces have made it increasingly difficult for persons not born into a ranching family to afford land and animals they need to establish a new livestock operation. In public lands states, pressures on state and federal budgets have reduced the number of job openings in range management even as members of the Baby Boom generation have begun to retire. At the same time, shifts in public opinion about the use of public rangelands for grazing have placed increasing pressure on ranchers who depend on such public land grazing for their livelihood. Rangeland decision makers struggle to find ways to counter these forces and sustain viable rangeland-based economies.

This research question has high priority because there are consequences to both society and the land itself. In the absence of a rangeland-based economy, abandoned lands can become degraded while properties nearer to population centers are more vulnerable to conversion to nonagricultural uses and the resulting loss of open space. Beneficiaries are not only those who work in natural resources or agriculture, but also open space advocates, conservationists, and small business. Ultimately the solutions to this problem must come from the policy realm. What decision makers need from scientific research are analyses of the costs, benefits, and potential long-term impacts of alternative policy interventions. Funding for such research might come from federal and state governments, conservation NGOs, and rural development organizations.

\section{Lessons learned}

As rangeland researchers at land grant universities, we have had innumerable interactions with land managers in our careers. Our research is conducted with an eye toward 
benefiting land manager stakeholders. However, in most cases we have chosen our research topics because they made scientific sense and could be funded by nonuniversity sources. Rarely have we had a chance to engage stakeholders in the process of choosing which studies to conduct. Even though the Future Directions for Usable Science for Rangeland Sustainability Workshop was not designed to identify research agendas specifically for ourselves, but rather for the profession generally, we benefited greatly by seeing how our work might be viewed through others' eyes. The experience of shared agenda-setting cannot help but shape the way we will think about future studies.

For that reason we would strongly encourage the scheduling of more workshops like the one held in Ardmore. A key feature of this particular workshop was that it produced a research agenda strongly directed toward the needs of livestock producers. This was understandable, given the mission of our hosts, the Samuel Roberts Noble Foundation, and the economic importance of private-land ranching in the southern Great Plains. It would be informative to convene workshops in other regions where different topics might arise as especially important-perhaps adapting to new energy economies in Montana, Wyoming, and the Dakotas, or conserving rare species in the public lands states. By the same token, it would be useful to engage a broader range of science users: extractive and renewable energy firms, hunting and recreational outfitters, small-tract rangeland owners, and others.

One of our workshop participants, Montague County, Texas, rancher Rooter Brite, made an interesting observation about how the perspectives of science producers and consumers differ: "Ranchers look at everything. Researchers look at specifics. We aren't going to make benefits for producers if we don't move from specifics to what it's all connected to." The connections made through Usable Science workshops can help bridge that gap between the habits of researchers and the science needs of stakeholders.

\section{References}

1. Hays, K.B., B.J. Leister, B.S. Rector, And L.D. White. 1998. Rangeland watersheds: the major source of water for Texans. Texas Agricultural Extension Service. Water for Texans. Series 1.

2. Byrd, K.B., L.E. Flint, P. Alvarez, C.F. Casey, B.M. Sleeter, C.E. Soulard, A.L. Flint, and T.L. Sohl. 2015. Integrated climate and land use change scenarios for California rangeland ecosystem services: wildlife habitat, soil carbon, and water supply. Landscape Ecology 30:729-750.

3. U.S. Energy Information Administration. 2014. Twelve states produced $80 \%$ of U.S. wind power in 2013. Today in
Energy. Available at: http://www.eia.gov/todayinenergy/detail. cfm?id=15851. Accessed 22 June 2015.

4. Kreuter, U.P., W.E. Fox, J.A. Tanaka, K.A. Maczko, D.W. McCollum, J.E. Mitchell, C.S. Duke, and L. Hidinger. 2012. Framework for comparing ecosystem impacts of developing unconventional energy resources on western US rangelands. Rangeland Ecology \&' Management 65:433-443.

5. Brunson, M.W., AND L. Huntsinger. 2008. Ranching as a conservation strategy: can old ranchers save the New West? Rangeland Ecology \& Management 61:137-147.

6. Havstad, K.M., D.P.C. Peters, R. Skaggs, J. Brown, B. Bestelmeyer, E. Fredrickson, J. Herrick, and J. Wright. 2007. Ecological services to and from rangelands of the United States. Ecological Economics 64:261-268.

7. Maczko, K., J.A. Tanaka, R. Breckenridge, L. Hidinger, H.T. Heintz, W.E. Fox, U.P. Kreuter, C.S. Duke, J.E. Mitchell, AND D.W. McCollum. 2011. Rangeland ecosystem goods and services: values and evaluation of opportunities for ranchers and land managers. Rangelands 33:30-36.

8. Dilling, L., And M.C. Lemos. 2011. Creating usable science: opportunities and constraints for climate knowledge use and their implications for science policy. Global Environmental Change 21:680-689.

9. Carroll, M.S., P.J. Cohn, D.N. Seesholtz, and L.L. HigGins. 2005. Fire as a galvanizing and fragmenting influence on communities: the case of the Rodeo-Chediski fire. Society E Natural Resources 18:301-320.

10. Rudeen, A.K., M.E. Fernandez-Gimenez, J.L. Thompson, And P. Meiman. 2012. Perceptions of success and the question of consensus in natural resource collaboration: lessons from an inactive collaborative group. Society $\&^{2}$ Natural Resources 25:10121027.

11. Byron, I., And A. Curtis. 2002. Maintaining volunteer commitment to local watershed initiatives. Environmental Management 30:59-67.

12. Epanchin-Niell, R.S., M.B. Hufford, C.E. Aslan, J.P. Sexton, J.D. Port, And T.M. Waring. 2009. Controlling invasive species in complex social landscapes. Frontiers in Ecology and the Environment 8:210-216.

13. Cutter, S.L., and C. Finch. 2008. Temporal and spatial changes in social vulnerability to natural hazards. Proceedings of the National Academy of Science 105:2301-2306.

Authors are Professor, Environment and Society Dept., Utah State University, Logan, UT 84322-5215 (Brunson, Mark.Brunson@) usu.edu); Professor, Environmental Science, Policy, and Management, University of California, Berkeley, CA 94720 (Huntsinger); Professor, Ecosystem Science and Management, Texas A\&M University, College Station, TX 77843-2120 (Kreuter); and Associate Professor, Agricultural and Applied Economics, University of Wyoming, Laramie, WY 82223-8543 (Ritten). 